\title{
Novel action of pituitary urocortin 2 in the regulation of expression and secretion of gonadotropins
}

\author{
Takahiro Nemoto, Naoko Yamauchi and Tamotsu Shibasaki \\ Department of Physiology, Nippon Medical School, 1-1-5 Sendagi, Bunkyo-ku, Tokyo 113-8602, Japan \\ (Correspondence should be addressed to T Nemoto; Email: taknemo@nms.ac.jp)
}

\begin{abstract}
Urocortins 2 (Ucn 2), one of the corticotropin releasing factor (CRF) peptide family, is thought to be an endogenous ligand for CRF type 2 receptor (CRF-R2). We previously demonstrated that Ucn 2 is expressed in the corticotrophs of rat pituitary, and the mRNA expression and secretion of $U \mathrm{cn}$ 2 in corticotrophs of rat anterior pituitary are regulated by CRF and glucocorticoids. Since CRF-R2 has been reported to be expressed on gonadotrophs of the rat pituitary, we hypothesized that pituitary Ucn 2 may control the expression and secretion of gonadotropins. Monolayer culture of rat anterior pituitary cells showed that the secretion of gonadotropins was suppressed by $U \mathrm{cn} 2$. A CRF-R2 selective antagonist, adenoviral-mediated expression of short interfering RNA against CRF-R2, and anti-Ucn 2 rabbit $\operatorname{IgG}$
\end{abstract}

increased the secretion and mRNA expression of gonadotropins. intraperitoneal injection of anti-Ucn 2 IgG into immature male rats significantly increased the secretion and mRNA expression of gonadotropins compared with those in normal rabbit IgG-injected rats. Daily i.p. injection of anti-Ucn 2 IgG into immature female rats induced a tendency toward earlier occurrence of menarche compared with normal rabbit IgG-injected rats. These findings suggest that pituitary Ucn 2 is involved in the regulatory mechanism of the expression and secretion of gonadotropins through its tonic and inhibitory action on gonadotrophs in a paracrine manner.

Journal of Endocrinology (2009) 201, 105-114

\section{Introduction}

Corticotropin-releasing factor (CRF) plays a key role in stress responses in the endocrine system, autonomic nervous system, behavior, and mood (Vale et al. 1981, Berkenbosch et al. 1987, Sapolsky et al. 1987). The various actions of CRF are induced through two subtypes of CRF receptor (CRF$\mathrm{R})$, the CRF-R1 and the CRF-R2, with a higher affinity to CRF-R1 than to CRF-R2 (Chen et al. 1993, Perrin et al. 1993, Lovenberg et al. 1995a). Urocortins 2 (Ucn 2), one of the CRF family peptides, is thought to be an endogenous ligand for CRF-R2 (Reyes et al. 2001). The results of several in vitro and in vivo experiments have shown that Ucn 2 induces; inhibition of the apoptosis of mesenteric arterial smooth muscle cells (Tao et al. 2006), an increase in cardiac output and in mean arterial pressure (Davis et al. 2007), a central CRF-R2-mediated inhibition of gastric emptying involving sympathetic $\alpha_{1}$-adrenergic mechanisms (Czimmer et al. 2006) and suppression of food intake (Zorrilla et al. 2004), and antagonizes the motor activation induced by CRF (Ohata \& Shibasaki 2004). Ucn 2-knockout mice exhibit significant increases in basal plasma ACTH and corticosterone levels, a significant decrease in fluid intake, and depressive-like behavior, increased insulin sensitivity, and protection from fat-induced insulin resistance (Chen et al. 2006a,b). However, the details of the physiological role of endogenous Ucn 2 still remain unclarified.

We previously demonstrated that Ucn 2 is expressed in the corticotrophs of rat pituitary but the concentrations of $U \mathrm{cn} 2$ in culture media of rat anterior pituitary cells are extremely low compared with those of ACTH (Nemoto et al. 2007). We also showed that the mRNA expression and secretion of $U_{c n}$ 2 in corticotrophs of rat anterior pituitary are regulated positively by CRF and negatively by glucocorticoids (Yamauchi et al. 2005, Nemoto et al. 2007). Two variants of CRF-R2, CRF-R2 $\alpha$ and CRF-R2 $\beta$, have been found in rats (Lovenberg et al. 1995b). CRF-R2 $\alpha$ is expressed in the hypothalamus, lateral septum, and raphe nuclei, whereas CRF-R2 $\beta$ is found in peripheral tissues such as heart, intestine, colon, and muscle (Lovenberg et al. 1995a). CRF$\mathrm{R} 2 \alpha$ has recently been shown to be expressed in more than $50 \%$ of gonadotrophs in rat anterior pituitary (Kageyama et al. 2003). We therefore hypothesized that pituitary Ucn 2 may be involved in the regulatory mechanism of the expression and secretion of gonadotropins in a paracrine manner.

To clarify the hypothesis, in this study, we examined the effects of Ucn 2 on the expression and secretion of gonadotropins, and the effects of a CRF-R2 antagonist, anti-Ucn 2 rabbit IgG, and adenoviral-mediated expression of short interfering RNA (siRNA) against CRF-R2 on the 
expression and secretion of gonadotropins in monolayercultured rat anterior pituitary cells. We further examined the effects of single or repeated i.p. injection of anti-Ucn 2 rabbit IgG on the expression and secretion of gonadotropins in male and female rats and the occurrence of menarche in female rats.

\section{Materials and Methods}

\section{Animals}

Male and female Wistar rats were maintained at $23 \pm 2{ }^{\circ} \mathrm{C}$ on a $12 \mathrm{~h}$ light: $12 \mathrm{~h}$ darkness cycle (light on at $0800 \mathrm{~h}$, off at $2000 \mathrm{~h}$ ). They were allowed access to chow and distilled water laboratory ad libitum. Menarche and the estrous cycle of female rats were determined by vaginal impedance measurements using an MK-10C (Muromachi Kikai Co. Ltd, Tokyo, Japan) and vaginal cytological findings. All experimental procedures were conducted in accordance with the guidelines for use and care of the Laboratory Animals Ethics Committee of Nippon Medical School.

\section{Primary culture of pituitary cells}

Male rats aged 6 weeks were killed by decapitation and their pituitary glands were removed under sterile conditions. The anterior and intermediate/posterior pituitaries were separately collected, and mechano-enzymatically dispersed as described previously with several modifications (Nemoto et al. 2007). Samples were washed twice in PBS and then incubated at room temperature in the PBS containing $0.047 \mathrm{~g} / 1 \mathrm{MgCl}_{2}, 0.1 \mathrm{~g} / \mathrm{CaCl}_{2}$, and $0.01 \%$ dispase (Godoshusei, Tokyo, Japan) with constant stirring for $30 \mathrm{~min}$. After washing dispersed cells with PBS three times a 1-ml aliquot of cell suspension containing $1.0 \times 10^{4}$ cells in a DMEM/F12 was placed in each well of 24 -well plates. The anterior pituitary cells obtained from 30 rats were cultured in 72 wells. The cells were subsequently allowed to attach to the surface of the wells in a humidified $95 \%$ air-5\% $\mathrm{CO}_{2}$ incubator for 4 days. On the day of the experiment the culture medium was changed. After $4 \mathrm{~h}$ incubation with samples, the culture medium from each well was collected. After centrifugation to remove debris at 3500 r.p.m. for $10 \mathrm{~min}$ at $4{ }^{\circ} \mathrm{C}$, the culture media were frozen and kept at $-80^{\circ} \mathrm{C}$ until assay. Total RNA was extracted using guanidium $\mathrm{HCl}$ from cells attached to the surface of wells.

\section{Recombinant adenovirus construction}

siRNAs against rat CRF-R1 (NM_030999), CRF-R2 $\alpha$ (NM_022714), and EGFP (U57608) were synthesized by Takara (Shiga, Japan). Each siRNA was cloned into pBAsimU6Neo DNA expression vector (Takara), and cut by EcoRV. The DNA fragments, which include siRNA expression unit, were then cloned into pAxcwit2 cosmid vector (Takara; pAx-siCRF-R1 and pAx-siCRF-R2).
Recombinant adenovirus was constructed by the COSTPC method using pAx-siCRF-R1 and pAx-siCRF-R2 cosmid according to the manufacturer's instruction (Takara).

\section{Recombinant CRF-R1 or CRF-R $2 \alpha$ expressing cells}

Rat CRF-R1 and CRF-R2 $\alpha$ cDNA were amplified from $\lambda$ TriplEx2 rat brain large-insert cDNA library (BD Biosciences Clontech) using CRF-R1: 5'-ggatcatgggacggcgccegcag- $3^{\prime}$ and $5^{\prime}$-ctcgagtcacactgctgtggactgcttg- $3^{\prime}$ and CRF-R2 $\alpha: 5^{\prime}$-agatctatggacgcggegctgctcctcag- $3^{\prime}$ and $5^{\prime}$-ctcgagtcacacggcagctgtctgcttg- $3^{\prime}$ primers. The amplified cDNA was subcloned into pGEM-T vector (Promega). Plasmid vector was digested by Bam $\mathrm{HI}$ and Xho I and cloned into pCMV-tag2B vector (FLAG-CRF-R1 and FLAG-CRFR2). Each plasmid was transfected into HeLa cells using Lipofectamine 2000. After $72 \mathrm{~h}$, HeLa cells overexpressing CRF-R1 or CRF-R2 were infected by recombinant adenovirus expressing siRNA against CRF-R1 or CRFR2. The cells were collected $72 \mathrm{~h}$ later and total RNA and protein were extracted. Specificities of siRNA against CRFR1 and CRF-R2 are shown in Fig. 3A and B. The effects of siCRF-R1 and siCRF-R2 on CRF-induced change in POMC mRNA expression and Ucn 2-induced gonadotropin secretion were studied. Cultured rat anterior pituitary cells infected by recombinant adenovirus expressing each siRNA were treated with $1 \mathrm{nM}$ CRF for $4 \mathrm{~h}$, and total RNA was extracted and POMC mRNA expression was analyzed by real-time RT-PCR. Cultured rat anterior pituitary cells infected by recombinant adenovirus expressing siRNA against CRF-R2 were also treated with Ucn 2 at concentrations of 1 , 10 , and $100 \mathrm{pM}$ for $4 \mathrm{~h}$, and concentrations of $\mathrm{LH}$ and FSH in the culture media were measured.

\section{RNA extraction and real-time PCR analyses}

Total RNA was extracted from monolayer-cultured pituitary cells and anterior pituitaries using Isogen (Takara). To avoid false positive results caused by DNA contamination, samples were treated with RNase-free DNase (Takara) for $60 \mathrm{~min}$ at $37^{\circ} \mathrm{C}$. First-strand cDNA was synthesized using $1 \mu \mathrm{g}$ of denatured total RNA at $42{ }^{\circ} \mathrm{C}$ for $60 \mathrm{~min}, 99^{\circ} \mathrm{C}$ for $5 \mathrm{~min}$, and $5{ }^{\circ} \mathrm{C}$ for 5 min using an ExScript RT reagent kit (Takara). PCR was performed by denaturation at $94{ }^{\circ} \mathrm{C}$ for $5 \mathrm{~s}$ and annealing extension at $60^{\circ} \mathrm{C}$ for $30 \mathrm{~s}$ for 40 cycles, using SYBR premix Ex Taq (Takara) and specific primers for rat Ucn 2, LH $\beta$-subunit, FSH $\beta$-subunit, and GAPDH (Table 1).

\section{Purification of anti-Ucn 2 rabbit $\operatorname{Ig} G$}

We had previously generated antiserum against mouse Ucn 2 (Yamauchi et al. 2005). Synthetic mouse Ucn 2 was coupled to porcine thyroglobulin through water soluble carbodiimide hydrochloride, and the conjugate was used to immunize female New Zealand white rabbits. The specificity of 
Table 1 Primer sequences of the studied genes

\section{Primers}

\section{Genes}

Ucn 2

$\mathrm{LH} \beta$

$\mathrm{FSH} \beta$

GAPDH

\author{
GAGCAACTCTAAAGCCAGCCCTTAC \\ TGATTCCTGGCAGCCTTGTTC \\ TGAGCCCAAGTGTGGTGTG \\ GGCAGCTGGCAGTACTCGAA \\ TGAACTGACCAACATCACCATCTC \\ CAGCCAGGCAATCTTATGGTCTC \\ GGCACAGTCAAGGCTGAGAATG \\ ATGGTGGTGAAGACGCCAGTA
}

Length (bp)

$384(169-285)$

$167(48-214)$

$189(66-254)$

$143(242-384)$
Accession number (GenBank)

NM_13385

NM_012858

NM_001007597

NM_017008
anti-Ucn 2 IgG has been described in the previous report (Yamauchi et al. 2005). The antiserum obtained after the fifth booster was used to purify $\operatorname{IgG}$ fraction with a protein A-sepharose column (Amersham Biosciences). The specificity of anti-Ucn 2 IgG against rat Ucn 2 was studied by dot blotting.

\section{Passive immunization}

Monolayer-cultured anterior pituitary cells were treated with $10 \mu \mathrm{g}$ anti-Ucn $2 \mathrm{IgG}$ or normal rabbit IgG. After 4, 8, and
$24 \mathrm{~h}$, culture media and cells were collected to examine FSH secretion and LH and FSH $\beta$-subunit mRNA expressions respectively. Twenty-one-day-old male rats were given an i.p. injection of 50 or $150 \mu \mathrm{g}$ anti-Ucn $2 \mathrm{IgG}$ or normal rabbit IgG. Rats were killed 8 or $24 \mathrm{~h}$ after injection and their trunk blood and pituitaries were collected to examine plasma $\mathrm{LH}$ and FSH concentrations and $\mathrm{LH}$ and $\mathrm{FSH} \beta$-subunit mRNA expressions respectively. Twenty-one-day-old female rats were injected daily (twice per day) with $100 \mu \mathrm{g}$ anti-Ucn 2 IgG or normal rabbit IgG until the second metestrus stage. Rats were killed and their trunk blood and tissues were collected at

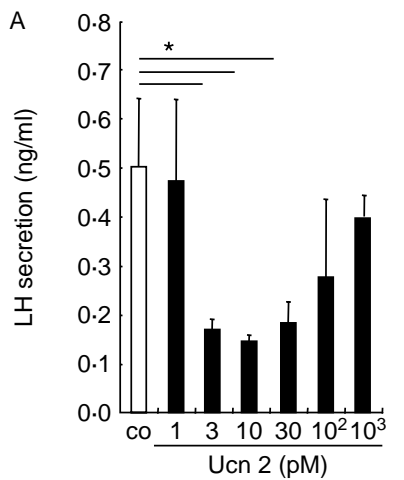

C

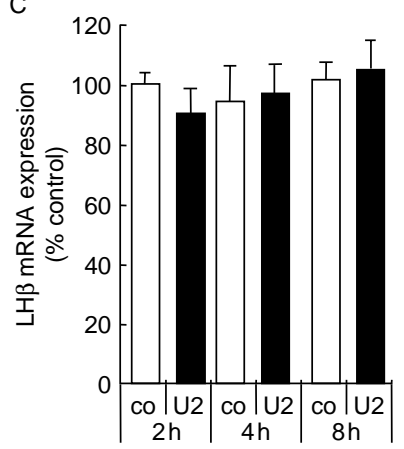

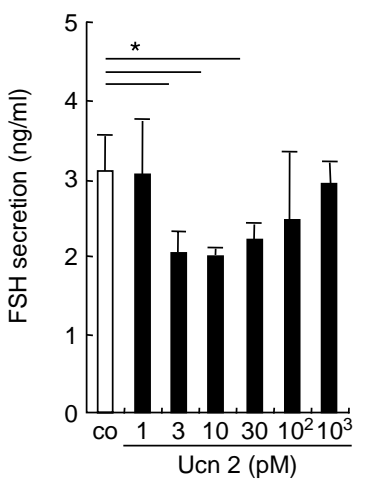

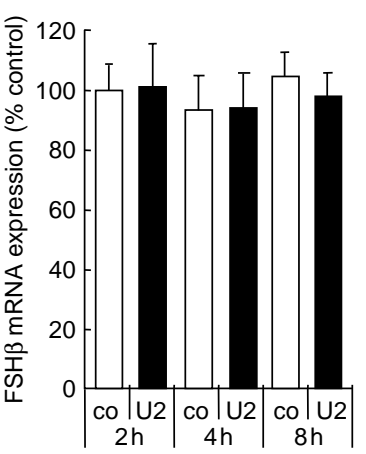

B
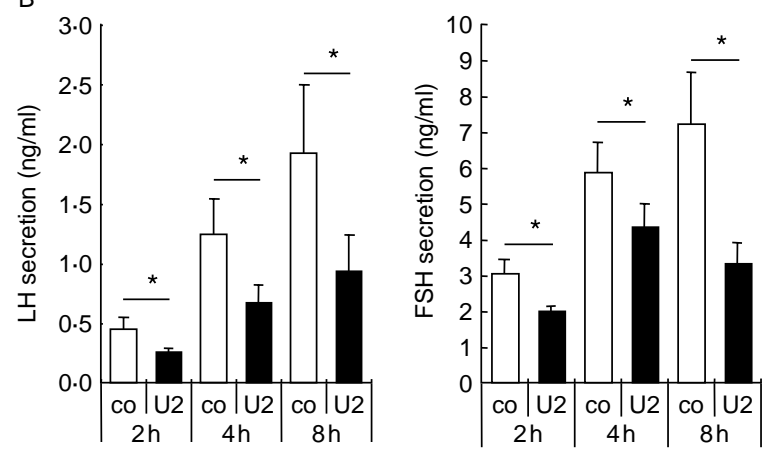

D

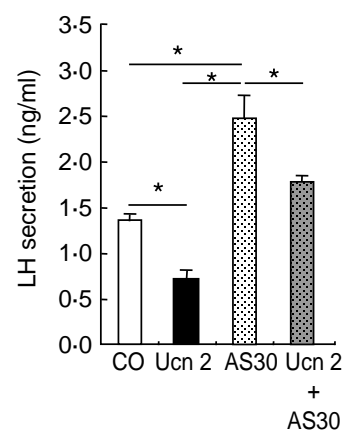

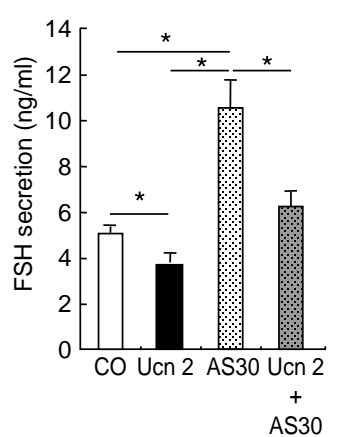

Figure 1 Ucn 2 suppresses gonadotropins secretion. Anterior pituitary cells were treated with Ucn 2 at concentrations of 1, 3, 10, 30, 100 , and $1000 \mathrm{pM}$ for $4 \mathrm{~h}$ or $10 \mathrm{pM}$ for 4, 8, and $24 \mathrm{~h}$. After incubation, culture media were collected for assays of LH and FSH (A, B). Total RNA was extracted from cells and assayed for levels of LH and FSH $\beta$-subunit mRNA expressions using the Thermal Cycler Dice Real Time PCR System (C). The cells were treated with $10 \mathrm{pM} \mathrm{Ucn} 2$ and/or $10 \mathrm{pM}$ antisauvagine-30 for $4 \mathrm{~h}$. After incubation, culture media were used for assays of $\mathrm{LH}$ and $\mathrm{FSH}(\mathrm{D})$. Values are the mean \pm s.E.M. There were six wells for each treatment. $* P<0 \cdot 05$, compared with control. Co, control; U2, Ucn 2; AS30, antisauvagine-30. 
the second metestrus stage, and plasma gonadotropin concentrations, anterior pituitary $\mathrm{LH}$ and FSH $\beta$-subunit mRNA expressions, and tissue weight were examined.

\section{Plasma hormone assay}

Rats were decapitated and trunk blood was collected in tubes containing EDTA $2 \mathrm{Na}(1 \mathrm{mg} / \mathrm{ml}$ blood $)$ and centrifuged at 3000 r.p.m. for $20 \mathrm{~min}$ at $4{ }^{\circ} \mathrm{C}$. Plasma of $1 \mathrm{ml}$ was transferred into $1.5 \mathrm{ml}$ Eppendorf tubes and stored at $-80{ }^{\circ} \mathrm{C}$ for measurement later. Rat plasma $\mathrm{LH}$ and FSH concentrations were measured using a rat $\mathrm{LH}\left[{ }^{125} \mathrm{I}\right]$ Biotrak assay system (Amersham Biosciences) and a rat FSH ELISA kit (Biocode, Liege, Belgium) respectively.

\section{Statistical analysis}

Statistical significance was performed using two-way ANOVA, unpaired $t$-test, and Mann-Whitney's U-test using Prism 5.0 (GraphPad Software, Inc., La Jolla, CA, USA). Cell culture in same experimental protocol was repeated two to four times and data were combined and analyzed. For real-time RT-PCR data, all results were combined for the statistical analysis and expressed as percent of controls. Statistical significance was established at the $P<0 \cdot 05$ level.

\section{Results}

Ucn 2 suppresses basal secretion of gonadotropins in primary culture of anterior pituitary cells

Since $4 \mathrm{~h}$ incubation of monolayered anterior pituitary cells with Ucn 2 significantly decreased LH and FSH secretion at concentrations of 3-30 pM (Fig. 1A), 10 pM of Ucn 2 was used in the following experiments. Secretion of LH and FSH was significantly suppressed by $2 \mathrm{~h}, 4 \mathrm{~h}$, and $8 \mathrm{~h}$ treatment with $10 \mathrm{pM}$ Ucn $2(42 \cdot 7 \pm 5 \cdot 3 \%$ for $2 \mathrm{~h}, 46 \cdot 0 \pm 13 \cdot 1 \%$ for $4 \mathrm{~h}$, and $51 \cdot 5 \pm 16 \cdot 0 \%$ for $8 \mathrm{~h}$ for $\mathrm{LH}$; and $33 \cdot 3 \pm 8 \cdot 3 \%$ for $2 \mathrm{~h}, 26 \cdot 8 \pm 9 \cdot 3 \%$ for $4 \mathrm{~h}$ and $54 \cdot 0 \pm 7 \cdot 7 \%$ for $8 \mathrm{~h}$ for $\mathrm{FSH}$ respectively: $P<0 \cdot 05, n=6$; Fig. $1 \mathrm{~B})$, although the mRNA expression of $\beta$-subunit of each gonadotropin was unchanged by $24 \mathrm{~h}$ treatment (Fig. 1C). Antisauvagine 30, a selective CRF-R2 antagonist, completely blocked Ucn 2-induced suppression of LH and FSH secretion (Fig. 1D).

\section{Gonadtropin secretion and $m R N A$ expression are increased by blockading $U_{c n} 2$ action in vitro and in vivo}

To clarify the role of endogenous Ucn 2 in the regulation of expression and secretion of gonadotropins, we examined the in vitro effects of antisauvagine-30 and recombinant adenovirus expressing siRNA and in vitro and in vivo effects of antiUcn 2 rabbit IgG on the secretion and mRNA expression of gonadotropins. Antisauvagine-30 significantly increased LH secretion in 4-h and 8 -h incubation $(1 \cdot 3 \pm 0 \cdot 1$-fold and $1 \cdot 3 \pm$ $0 \cdot 1$-fold respectively: $P<0 \cdot 05, n=6$; Fig. $2 \mathrm{~A})$ and its $\beta$-subunit mRNA expression in $8 \mathrm{~h}$ and $24 \mathrm{~h}$ incubation $(2 \cdot 1 \pm 0 \cdot 3$-fold and $1 \cdot 7 \pm 0 \cdot 1$-fold respectively: $P<0 \cdot 05$, $n=6$; Fig. 2B). Antisauvagine-30 also significantly increased FSH secretion in $4 \mathrm{~h}$ and $8 \mathrm{~h}$ incubation $(1 \cdot 4 \pm 0 \cdot 1$-fold and 1.4 \pm 0.1-fold respectively: $P<0 \cdot 05, n=6$; Fig. 2 A) and its $\beta$-subunit mRNA expression in $8 \mathrm{~h}$ and $24 \mathrm{~h}$ incubation $(1 \cdot 8 \pm 0 \cdot 3$-fold and $1 \cdot 8 \pm 0 \cdot 1$-fold respectively: $P<0 \cdot 05$, $n=6$; Fig. 2B).

Specificities of siRNA against CRF-R1 and CRF-R2 were shown in Fig. 3. Recombinant adenovirus expressing siRNA against CRF-R2 significantly suppressed CRF-R2 mRNA expression by $79.5 \pm 6 \cdot 0 \%(P<0 \cdot 05, n=4)$ and protein by $78 \cdot 8 \pm 13 \cdot 5 \%(P<0 \cdot 05, n=4$; Fig. $3 \mathrm{~A}$ and $\mathrm{B})$ with significant suppression of CRF-R1 mRNA expression by $57 \cdot 7 \pm 3 \cdot 6 \%(P<0 \cdot 05, n=4)$ and no significant effect on CRF-R1 protein, while recombinant adenovirus expressing siRNA against CRF-R1 significantly decreased CRF-R1 mRNA by $67 \cdot 9 \pm 8 \cdot 0 \%(P<0 \cdot 05, n=4)$ and protein by $63 \cdot 5 \pm 3 \cdot 8 \%(P<0 \cdot 05, n=4)$ without significant effect on CRF-R2 mRNA or protein as shown in Fig. 3A and 3B. The
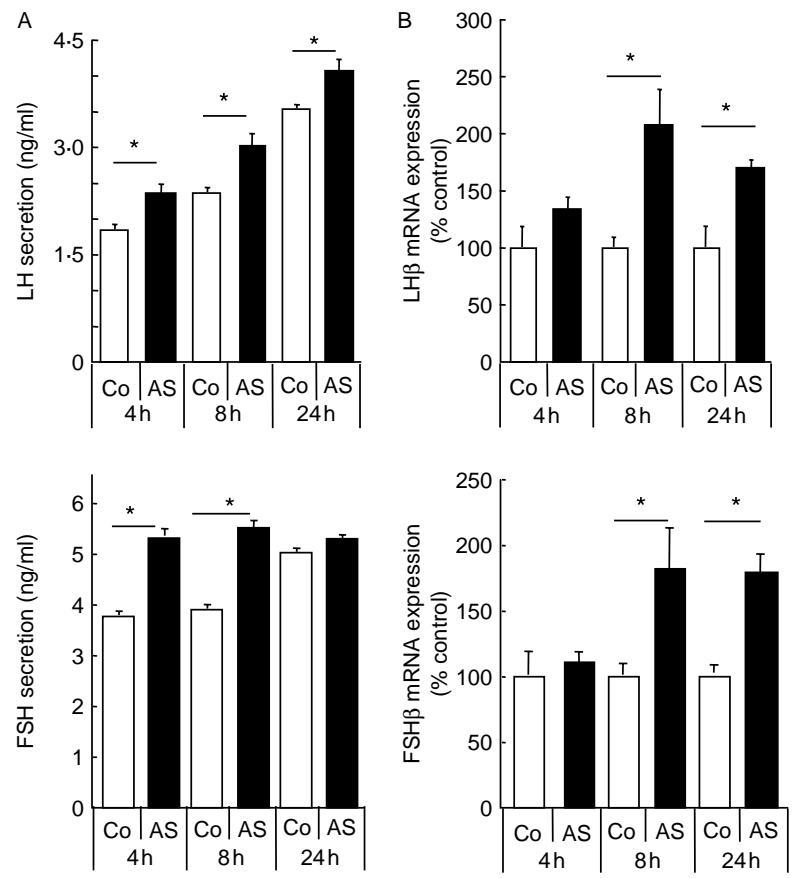

Figure 2 CRF-R2 antagonist increases gonadotropins secretion and their $\beta$-subunit mRNA expression in vitro. Anterior pituitary cells were treated with antisauvagine-30 (AS) at a concentration of $10 \mathrm{pM}$ or vehicle $(\mathrm{Co})$ for 4,8 , and $24 \mathrm{~h}$. After incubation, culture media were collected and used for assays of LH and FSH (A), and cells were analyzed for their $\beta$-subunit mRNA expression using the Thermal Cycler Dice Real Time PCR System (B). Values are the mean \pm S.E.M. There were four wells for each treatment. ${ }^{*} P<0 \cdot 05$, compared with control. 
effects of siCRF-R1 and siCRF-R2 on CRF-induced change in POMC mRNA expression were studied (Fig. 3C). siRNA against CRF-R1 significantly suppressed CRF-induced expression of POMC mRNA, while siRNA against CRFR2 did not affect the CRF-induced POMC mRNA expression. Recombinant adenovirus expressing siRNA against CRF-R2, but not CRF-R1, significantly increased $\mathrm{LH}$ and $\mathrm{FSH}$ secretion $(1 \cdot 3 \pm 0 \cdot 1$-fold and $1 \cdot 4 \pm 0 \cdot 1$-fold respectively: $P<0 \cdot 05, n=4$; Fig. $4 \mathrm{~A})$ and $\mathrm{LH}$ and $\mathrm{FSH}$ $\beta$-subunit mRNA expressions $(2 \cdot 3 \pm 0 \cdot 1$-fold and $1 \cdot 4 \pm 0 \cdot 1-$ fold respectively: $P<0 \cdot 05, n=4$; Fig. 4B). Moreover, the suppression of CRF-R2 mRNA expression by siRNA blocked Ucn 2-induced suppression of LH and FSH secretion (Fig. 4C). These results indicate that recombinant adenovirus expressing siRNA against CRF-R1 or CRF-R2 was specifically active for the suppression of each CRF-R subtype.

The cross-reactivity of the anti-Ucn 2 antiserum used for the present study with rat Ucn 2 is $83 \cdot 3 \%$ at ED50\% in RIA (Yamauchi et al. 2005). As shown in Fig. 5, anti-Ucn 2 IgG at a concentration of $10 \mu \mathrm{g} / \mathrm{ml}$ was able to detect $100 \mathrm{pg}$ of rat Ucn 2 and the binding was completely abolished by preincubation of anti-Ucn $2 \operatorname{IgG}$ with $10 \mu \mathrm{g}$ rat Ucn 2 .
Anti-Ucn 2 IgG significantly increased FSH secretion (1.4 \pm $0 \cdot 1$-fold: $P<0 \cdot 05, n=6)$ and its $\beta$-subunit mRNA expression with 24-h incubation compared with those of normal rabbit IgG treatment $(2 \cdot 3 \pm 0 \cdot 1$-fold: $P<0 \cdot 05, n=6$; Fig. 6). Anti-Ucn $2 \mathrm{IgG}$ also significantly increased LH $\beta$-subunit mRNA expression in 8 - $\mathrm{h}$ and $24-\mathrm{h}$ incubation compared with that of normal rabbit $\operatorname{IgG}$ treatment $(2 \cdot 9 \pm$ $0 \cdot 5$-fold for $8 \mathrm{~h}$, and $3 \cdot 1 \pm 0 \cdot 3$-fold for $24 \mathrm{~h}$ respectively: $P<0 \cdot 05, n=6$; Fig. 6). The concentrations of $\mathrm{LH}$ in culture media could not be measured by rat LH $\left[{ }^{125} \mathrm{I}\right]$ Biotrak assay system because of interference by rabbit $\operatorname{IgG}$ in the assay system.

A single i.p. injection of anti-Ucn 2 IgG into 3-week-old male rats significantly increased plasma LH $(1 \cdot 2 \pm 0 \cdot 1$-fold for $150 \mu \mathrm{g}$ IgG: $P<0 \cdot 05, n=9)$ and plasma FSH levels $(1 \cdot 3 \pm$ $0 \cdot 1$-fold for $50 \mu \mathrm{g}$ and $1 \cdot 4 \pm 0 \cdot 0$-fold for $150 \mu \mathrm{g}$ respectively: $P<0 \cdot 05, n=9), 24 \mathrm{~h}$ after the injection compared with those of normal rabbit IgG-injected rats (Fig. 7A and B). Anti-Ucn $2 \mathrm{IgG}$ at a dose of $150 \mu \mathrm{g}$ also significantly increased $\beta$-subunit mRNA expression of LH and FSH $24 \mathrm{~h}$ after the injection compared with normal rabbit IgG-injected rats $(1 \cdot 8 \pm 0 \cdot 1$-fold for $\mathrm{LH}$ and $2 \cdot 4 \pm 0 \cdot 1$-fold for FSH: $P<0 \cdot 05$, $n=9$; Fig. $7 \mathrm{C}$ and D).
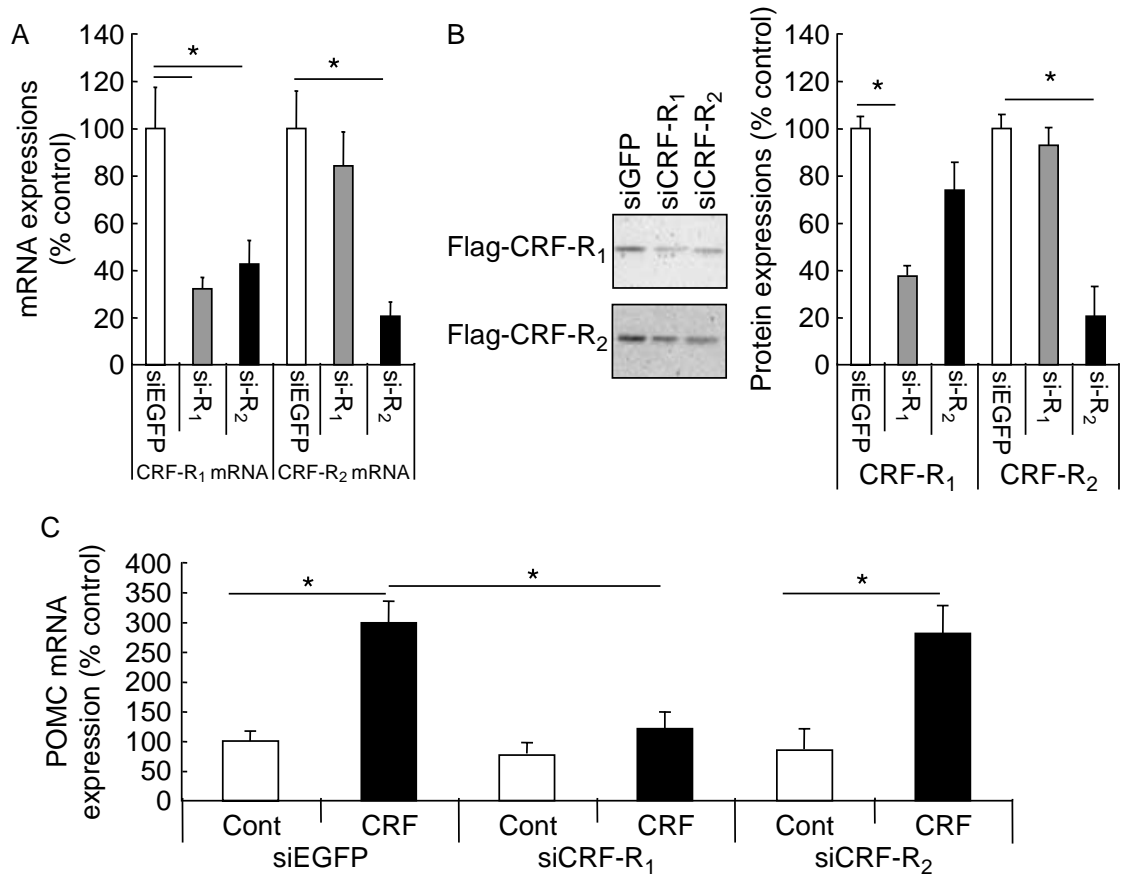

Figure 3 Specificity of siRNA against CRF-R1 and CRF-R2. Adenovirus expressing siRNA against CRF-R1 or CRF-R2 were added to culture media of rat anterior pituitary cells at $10^{6}$ MOI. After $72 \mathrm{~h}$ incubation, cells were analyzed for CRF-R1 and CRF-R2 mRNA and their proteins (A and B). There were four wells for each treatment. Effects of CRF-R1 or CRF-R2 suppression on CRF-induced POMC mRNA expression were examined (C). Adenovirus expressing siRNA against CRF-R1 or CRF-R2 were added to culture media of anterior pituitary cells at $10^{6} \mathrm{MOI}$. After $72 \mathrm{~h}$ incubation, cells were treated with $1 \mathrm{nM}$ CRF for $4 \mathrm{~h}$. There were six wells for each treatment. 

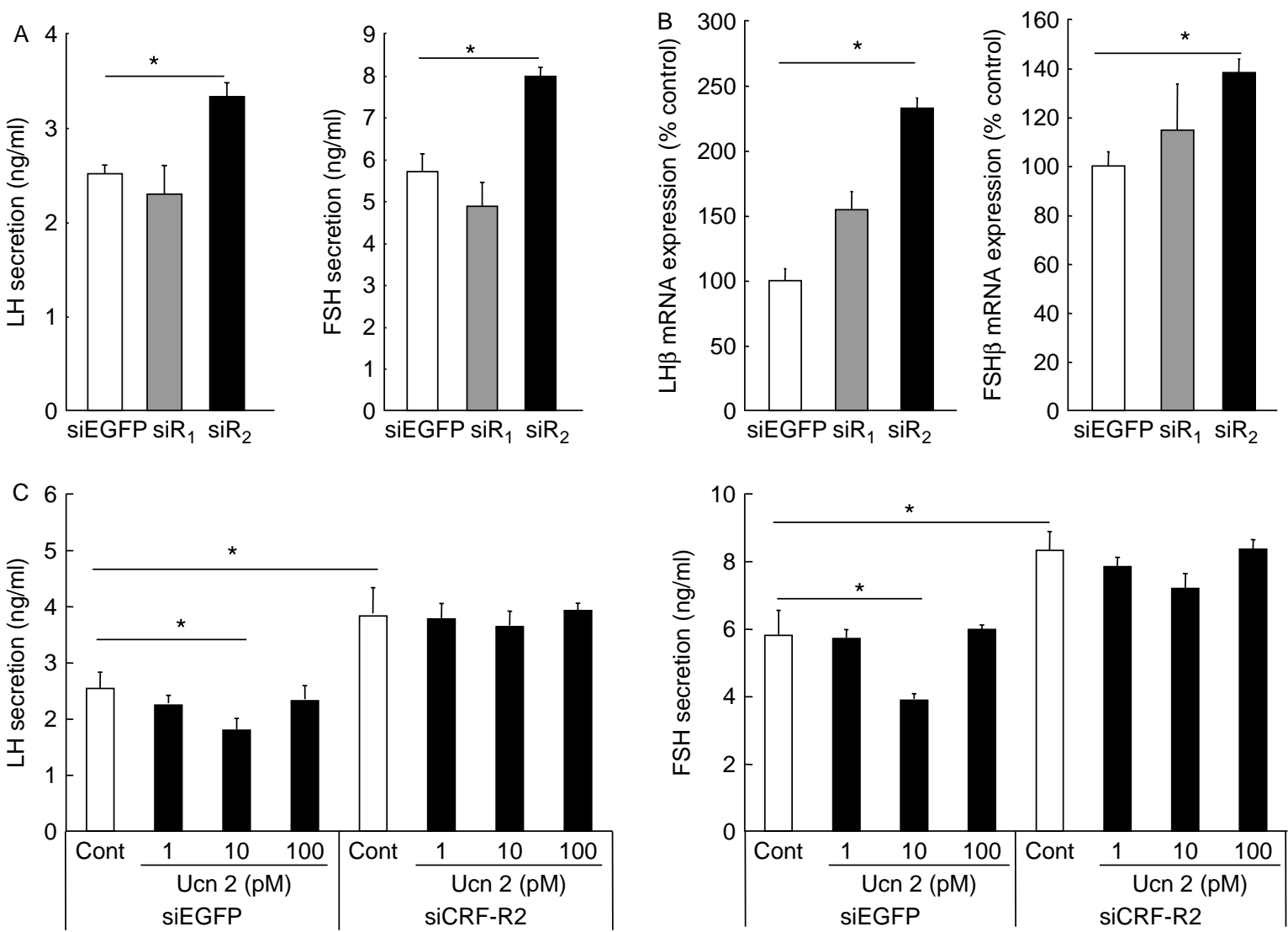

Figure 4 Adenovirus expressing siRNA against CRF-R2 increases gonadotropins secretion and their $\beta$-subunit mRNA expression in vitro. Adenovirus expressing siRNA against CRF-R1 and CRF-R2 was added to culture media of anterior pituitary cells at $10^{6} \mathrm{MOI}$. After $72 \mathrm{~h}$, basal LH and FSH secretion in anterior pituitary cells infected by adenovirus expressing siRNA against CRF-R1 or CRF-R2 for $4 \mathrm{~h}$ were measured (A). Total RNA was extracted from cells and analyzed for gonadotropin $\beta$-subunit mRNA expression (B). After 4-h treatment with Ucn 2 at concentrations of 1, 10, and $100 \mathrm{pM}$, culture media were collected and assayed for LH and FSH (C). Values are the mean \pm s.E.M. There were six wells for each treatment. ${ }^{*} P<0 \cdot 05$, compared with control siRNA expressing adenovirus (siEGFP).

Anti-Unn 2 IgG induced a tendency toward earlier occurrence of menarche in female rats

A tendency toward earlier occurrence of menarche was found in anti-Ucn 2 IgG-injected female rats compared with that of normal rabbit IgG-injected rats $(41 \cdot 7 \pm 0.5$ days after birth versus $43 \cdot 3 \pm 0 \cdot 8$ days after birth: $P=0.0973$, MannWhitney $U=28 \cdot 00, n=10)$. Seventy percent of anti-Ucn 2 IgG-injected female rats (7 out of 10) exhibited menarche by day 42 while $40 \%$ of normal rabbit IgG-injected rats (4 out of 10) did by that day (Fig. 8C), although their body weight and pituitary, ovarian, and uterine weights as ratios of body weight, and time of vaginal opening and estrous cycle did not differ (Fig. 8A-C). Daily i.p. injection of anti-Ucn $2 \mathrm{IgG}$ showed a tendency toward an increase in plasma FSH $(P=0 \cdot 0625)$, although plasma LH was unchanged. This treatment slightly increased LH and FSH $\beta$-subunit mRNA expression, although the change was not statistically significant (Fig. 8D).
Rat Ucn 2

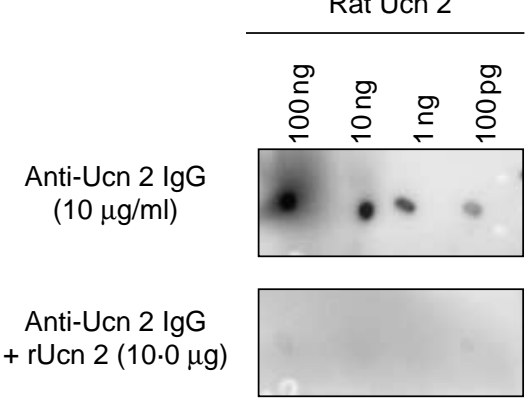

Figure 5 Immunoneutralization of anti-Ucn 2 lgG with rat $U \mathrm{cn} 2$. Rat Ucn 2 blotted at doses of $100 \mathrm{ng}, 10 \mathrm{ng}, 1 \mathrm{ng}$, and $100 \mathrm{pg}$ was detected by anti-Ucn $2 \mathrm{lgG}$ at a concentration of $10 \mu \mathrm{g} / \mathrm{ml}$. The antibody against mouse Ucn 2 was able to detect 100 pg rat Ucn 2. The signals were abolished by 30-minute preincubation of anti-Ucn $2 \lg \mathrm{w}$ with rat Ucn 2 at a dose of $10 \mu \mathrm{g}$. 

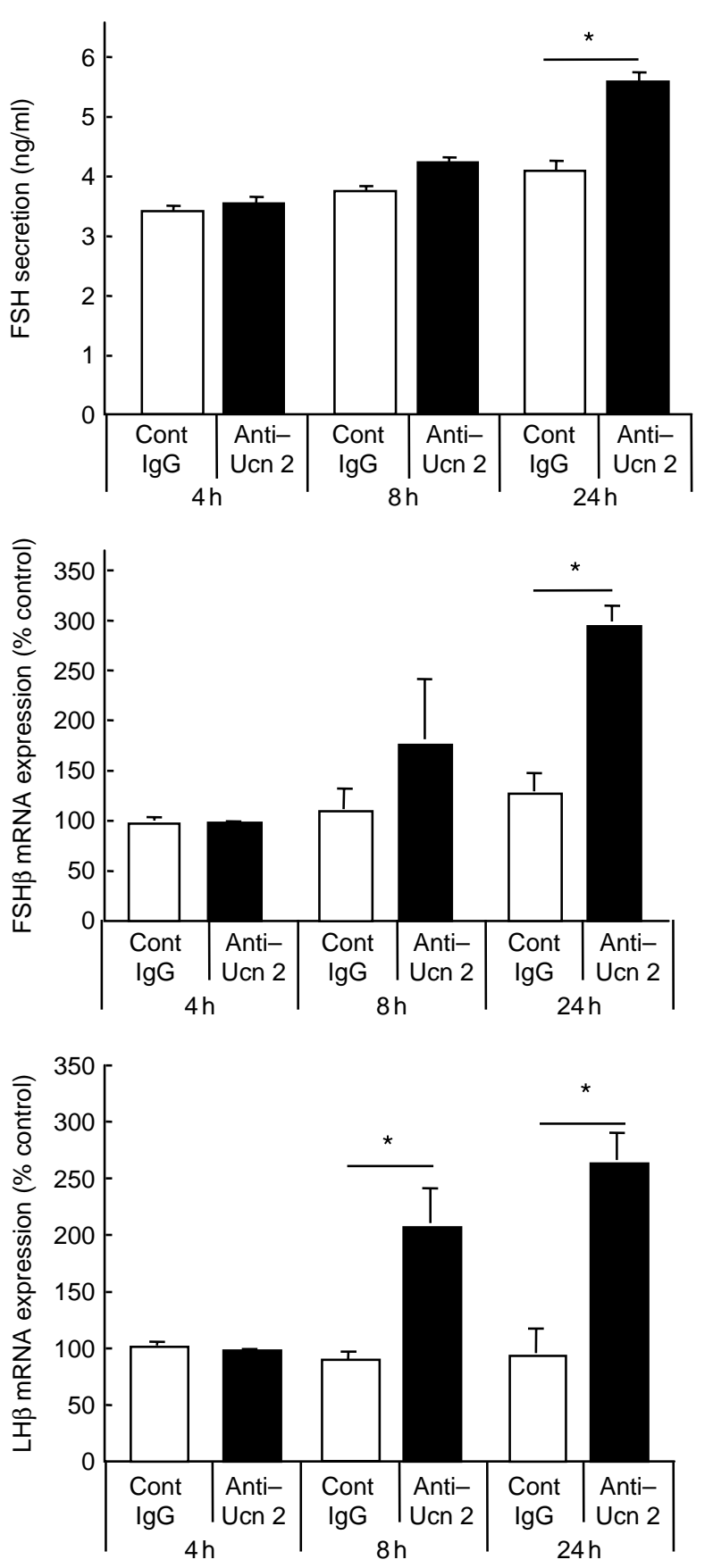

Figure 6 Anti-Ucn 2 lgG increases gonadotropin secretion and their $\beta$-subunit mRNA expression in vitro. Anterior pituitary cells were treated with $10 \mu \mathrm{g} / \mathrm{ml}$ of anti-Ucn $2 \lg \mathrm{G}$ (Anti-Ucn 2) or normal rabbit IgG (Cont IgG) for 4, 8, and 24 h. After incubation, culture media were collected and assayed for FSH and cells were analyzed for gonadotropin $\beta$-subunit mRNA expression. Values are the mean \pm s.E.M. There were six wells for each treatment. ${ }^{*} P<0 \cdot 05$, compared with normal rabbit IgG injection.

\section{Discussion}

We previously reported that Ucn 2 is biosynthesized by corticotrophs of rat anterior pituitary, and that the mRNA expression level and secretion of Ucn 2 in corticotrophs are positively and negatively regulated by CRF and glucocorticoids respectively (Nemoto et al. 2007). Although CRF-R2, which is bound by Ucn 2, is reported to be expressed mainly on gonadotrophs in rat anterior pituitary (Kageyama et al. 2003), it has been unclear whether Ucn 2 modulates the expression and secretion of gonadotropins. The present study has shown that Ucn 2 suppresses the secretion of gonadotropins in vitro, and that its action is blocked by antisauvagine30, a CRF-R2 selective antagonist. These results indicate that Ucn 2 inhibits gonadotropins secretion through CRF-R2.

Our findings also showed that adenovirus expressing siRNA against CRF-R2 and a CRF-R2 antagonist each significantly increased $\mathrm{LH}$ and FSH secretion and their $\beta$-subunit mRNA expression in vitro. Furthermore, in vitro and in vivo passive immunization experiments using specific anti-Ucn 2 IgG revealed increases in the secretion of gonadotropins and their $\beta$-subunit mRNA expression. Our previous study showed that concentrations of Ucn 2 in the culture media of rat anterior pituitary cells are extremely low, at only a few percent of those of ACTH (Nemoto et al. 2007). Together with these results, the present findings thus suggest that pituitary $U_{c n} 2$ tonically inhibits the expression and secretion of gonadotropins through CRF-R2 in a paracrine fashion.

The dose-response curve found in the present study was U-shaped, and the effective doses for Ucn 2 to inhibit gonadotropins secretion were 3-30 pM. The reported average EC50 value for CRF-R2 activation of Ucn 2 is $0 \cdot 14(0 \cdot 03-0.52) \mathrm{nM}$ (Reyes et al. 2001). The difference in the effective doses of Ucn 2 between the studies may be induced by the cells and the marker of cell response used for each study, normal rat anterior pituitary cells and gonadotropins for our study, and Chinese hamster ovary cells and cAMP for the latter study.

Ucn 2 inhibited the secretion of gonadotropins without changing the mRNA expression level of gonadotropins, while the reduction in CRF-R2 by siCRF-R2 and the blockade of endogenous Ucn 2 action by antisauvagine-30 or anti-Ucn $2 \operatorname{IgG}$ increased both the secretion and the mRNA expression of gonadotropins. These findings may suggest that the expression level of gonadotropin mRNA is already suppressed by endogenous Ucn 2 secreted by POMC cells, and that the exogenous Ucn 2 could not induce further inhibition of the gene expression. By contrast, since the basal secretion of gonadotropins gradually increased during the incubation as shown in Fig. 1B, the inhibitory effect of endogenous Ucn 2 seems to be weak on the secretion of gonadotropins. Furthermore, the intracellular signals that participate in the regulatory mechanisms of secretion of gonadotropins and their gene expression may be different, 

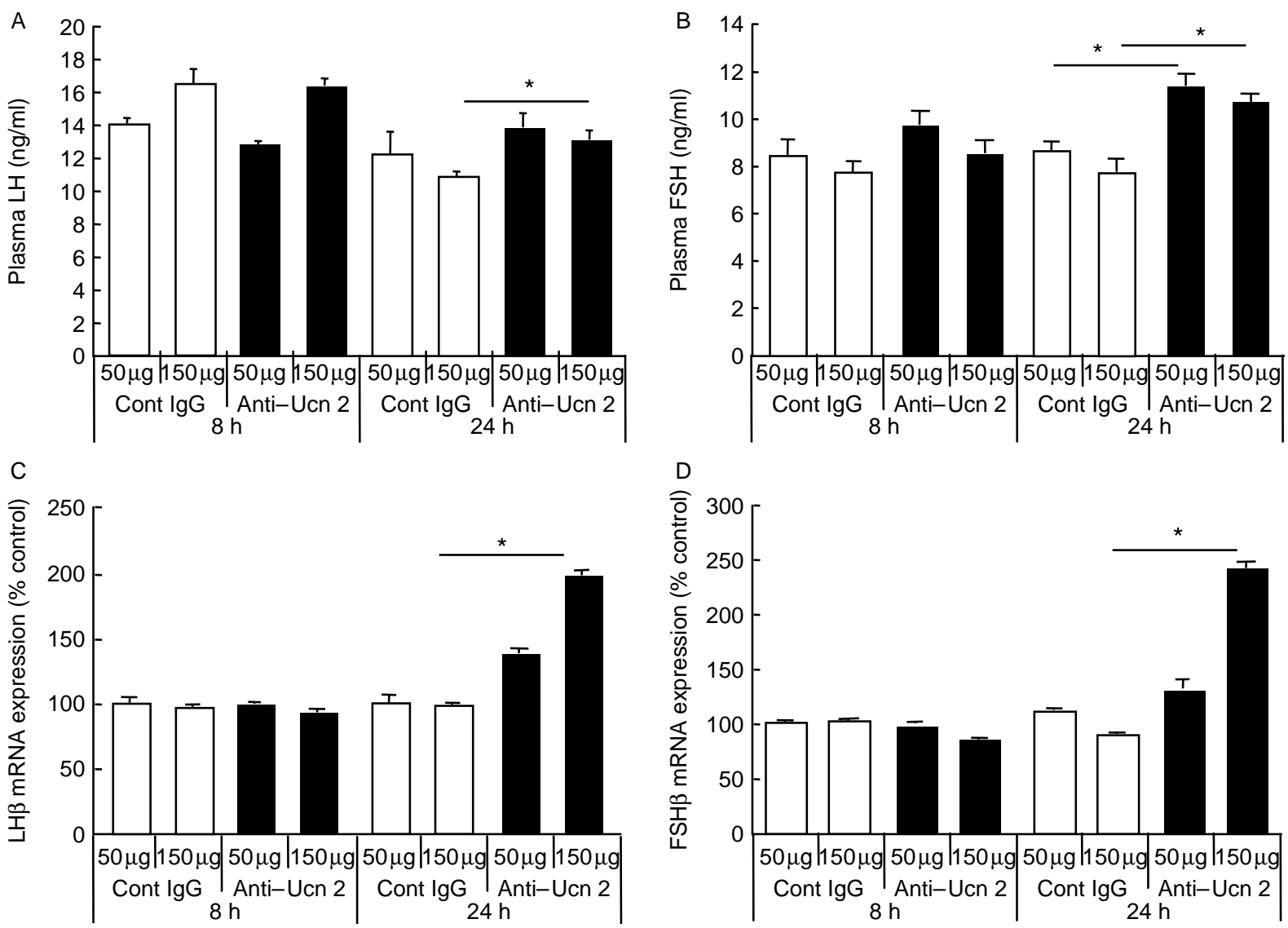

Figure 7 Anti-Ucn 2 lgG increases secretion by gonadotropins and their $\beta$-subunit mRNA expression in vivo. Twenty-one-day-old male rats were injected i.p. with anti-Ucn 2 IgG (Anti-Ucn 2; 50 or $150 \mu \mathrm{g}$ ) or normal rabbit IgG (Cont IgG; 50 or $150 \mu \mathrm{g}$ ). After 8 and $24 \mathrm{~h}$, rats were killed by decapitation and trunk blood was collected for plasma $\mathrm{LH}(\mathrm{A})$ and FSH (B) assays. Total RNA was extracted from anterior pituitary and used for studies of $\mathrm{LH}(\mathrm{B})$ and $\mathrm{FSH}(\mathrm{C}) \beta$-subunit mRNA expression levels using the Thermal Cycler Dice Real Time PCR System. Values are the mean \pm S.E.M. There were six rats for each treatment. ${ }^{*} P<0 \cdot 05$, compared with normal rabbit IgG injection.

thus causing the different changes in the secretion and gene expression of gonadotropins in response to $U \mathrm{cn} 2$.

Menarche is one of the main manifestations of puberty. Daily injection of anti-Ucn $2 \operatorname{IgG}$ into immature female rats starting at the age of 21 days induced a tendency toward earlier occurrence of menarche compared with normal rabbit IgG-injected rats. Prior to puberty, circulating levels of gonadotropins are very low, due to the suppression of $\mathrm{GnRH}$ release from the hypothalamus via two possible mechanisms: a central inhibitory mechanism that has not yet been specified and a peripheral mechanism that is mediated by the negative feedback effect of gonadal steroids (Wennink et al. 1990, Ebling 2005). As puberty draws near, the pulsatility of release of the two gonadotropins is increased, and with the onset of puberty the pulsatile release of them is amplified. These changes in gonadotropin secretion reflect increased pulsatile secretion of $\mathrm{GnRH}$, and the increases in circulating gonadotropin levels stimulate follicle maturation and estrogen synthesis in the ovaries. It has been hypothesized that before puberty, the hypothalamus is extremely sensitive to estrogen, the levels of which are very low in blood (Mauras et al. 1996, Ebling 2005). In addition to the high sensitivity of the hypothalamus to estrogen, suppression of the secretion of gonadotropins from gonadotrophs also occurs before puberty (Foster et al. 2006). The findings of the present study suggest that pituitary Ucn 2 may play some role in the suppression of gonadotropin secretion before puberty. Since Ucn 2 is secreted by corticotrophs that secrete ACTH in response to stress, Ucn 2 may be involved in stress-induced gonadal dysfunction.

Anti-Ucn 2 IgG increased LH $\beta$-subunit mRNA expression after $8 \mathrm{~h}$ or $24 \mathrm{~h}$ period of incubation in cultured anterior pituitary cells, while it increased FSH $\beta$-subunit mRNA expression only after $24 \mathrm{~h}$ period of incubation as shown in Fig. 6. Plasma FSH was increased by both 50 and $150 \mu \mathrm{g}$ of anti-Ucn 2 IgG injection, while plasma LH and pituitary LH and FSH $\beta$-subunit mRNA expressions were increased only by $150 \mu \mathrm{g}$ of anti-Ucn 2 IgG injection as shown in Fig. 7. The findings presented indicate that the gene expression and the secretion of $\mathrm{LH}$ and those of FSH are 

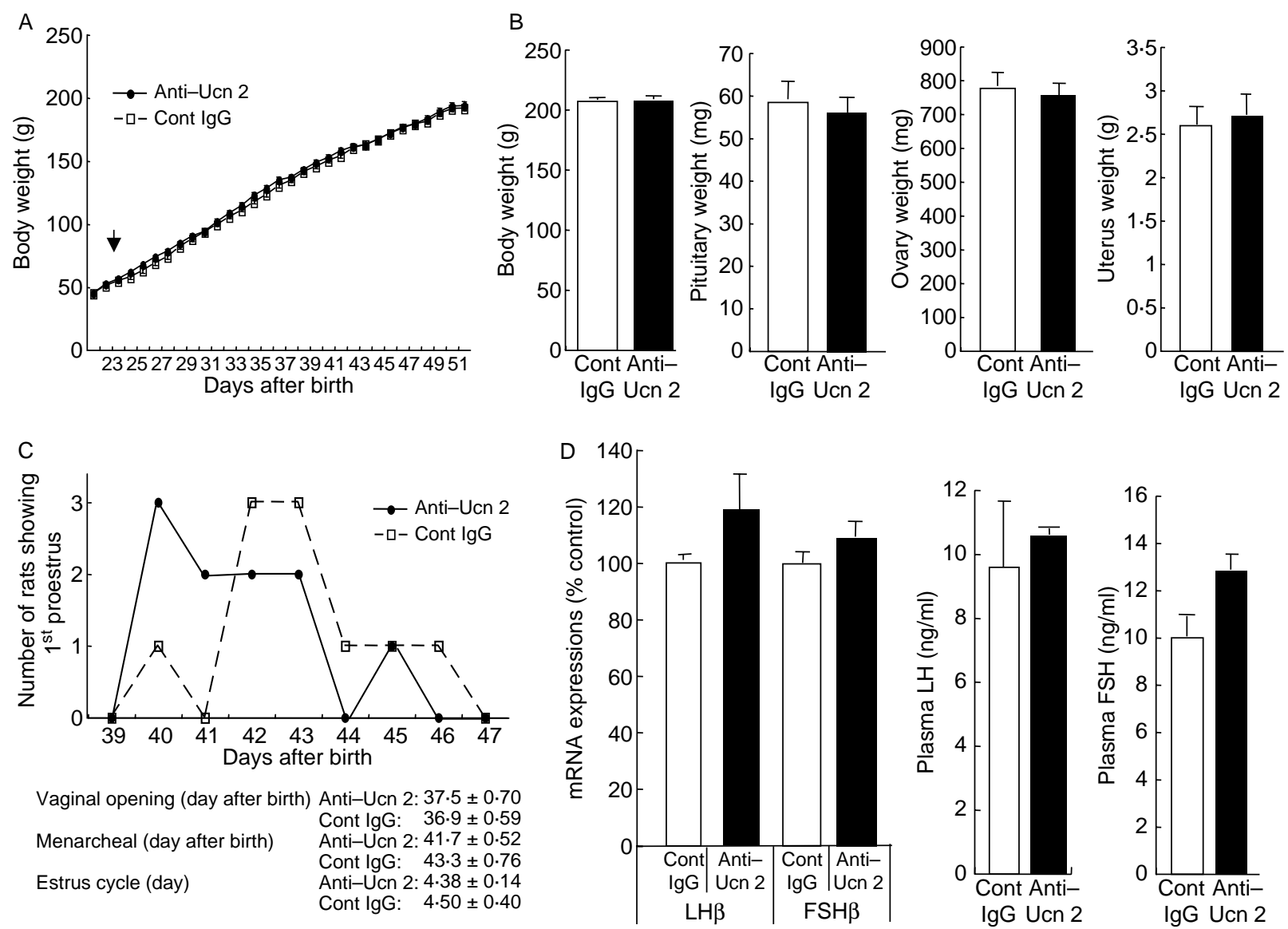

Figure 8 Repeated i.p. injection of anti-Ucn 2 lgG into immature female rats shows earlier occurrence of menarche. Twenty-one-day-old female rats were injected i.p. with anti-Ucn 2 IgG (Anti-Ucn 2; $100 \mu \mathrm{g} /$ twice a day) or normal rabbit lgG (Cont lgG; $100 \mu \mathrm{g} / \mathrm{twice}$ per day). Body weight $(\mathrm{A})$ and vaginal impedance $(\mathrm{C})$ were measured at 0900 and $1330 \mathrm{~h}$ every day respectively (A). Metestrus rats were killed by decapitation, and the pituitary, ovaries, and uterus were removed and weighed (B). Plasma samples were separated for assays of LH and FSH (D). Total RNA was extracted from anterior pituitary and assayed for levels of Ucn 2 and $\mathrm{LH}$ and FSH $\beta$-subunit mRNA expressions using the Thermal Cycler Dice Real Time PCR System (D). Values are the mean \pm s.E.M. There were ten rats for each treatment. ${ }^{*} P<0 \cdot 05$, compared with normal rabbit IgG injection.

differentially regulated by Ucn 2 . In addition, as shown in Fig. 8, a tendency toward an increase in plasma FSH $(P=0.0625)$ was found in female rats injected daily with anti-Ucn $2 \mathrm{IgG}$, while plasma LH was unchanged by the same treatment. These results are presumably due to the different responsiveness of each gonadotropin to $\mathrm{GnRH}$ and the complex mechanisms of regulation of mRNA transcription of gonadotropins (Shupnik 1996). It is generally accepted that the mechanisms of regulation of $\mathrm{LH}$ and FSH secretion and their $\beta$-subunit mRNA expression are complex, and that differences in mechanisms of regulation between the two gonadotropins may have been responsible for the differences in responses to anti-Ucn 2 IgG observed in the present study (MacNeilly et al. 2003, Winters \& Moore 2007).

A recent study has found that earlier occurrence of menarche is associated with increases in body mass index, elevation of plasma insulin levels, and elevation of blood pressure in humans (Kaplowitz 2008). Although it has been reported that $U \mathrm{cn} 2$ reduces glucose utilization and insulin sensitivity (Chen et al. 2006b), we found no significant change in serum insulin or plasma glucose levels in the anti-Ucn 2 IgG-injected rats (data not shown). Our findings therefore suggest that neither hyperinsulinemia nor hyperglycemia is related to the tendency toward earlier occurrence of menarche in anti-Ucn 2 IgG-treated rats.

In conclusion, the findings of our both in vitro and in vivo experiments suggest that Ucn 2 secreted by POMC cells acts on gonadotrophs through CRF-R2 in a paracrine fashion to tonically inhibit the expression and secretion of gonadotropins.

\section{Declaration of interest}

The authors declare that there is no conflict of interest that could be perceived as prejudicing the impartiality of the research reported.

Journal of Endocrinology (2009) 201, 105-114 


\section{Funding}

This study was supported in part by Health and Labor Sciences Research Grants from the Ministry of Health, Labor and Welfare and Grants-in-Aid for Scientific Research from the Ministry of Education, Science and Culture of Japan.

\section{References}

Berkenbosch F, van Oers J, del Rey A, Tilders F \& Besedovsky H 1987 Corticotropin-releasing factor-producing neurons in the rat activated by interleukin-1. Science 238 524-526.

Chen R, Lewis KA, Perrin MH \& Vale WW 1993 Expression cloning of a human corticotropin-releasing-factor receptor. PNAS 90 8967-8971.

Chen A, Brar B, Choi CS, Rousso D, Vaughan J, Kuperman Y, Kim SN, Donaldson C, Smith SM, Jamieson P et al. 2006a Urocortin 2 modulates glucose utilization and insulin sensitivity in skeletal muscle. PNAS $\mathbf{1 0 3}$ 16580-16585.

Chen A, Zorrilla E, Smith S, Rousso D, Levy C, Vaughan J, Donaldson C, Roberts A, Lee KF \& Vale W $2006 b$ Urocortin 2-deficient mice exhibit gender-specific alterations in circadian hypothalamus-pituitary-adrenal axis and depressive-like behavior. Journal of Neuroscience 26 5500-5510.

Czimmer J, Million M \& Tache Y 2006 Urocortin 2 acts centrally to delay gastric emptying through sympathetic pathways while CRF and urocortin 1 inhibitory actions are vagal dependent in rats. American Journal of Physiology. Gastrointestinal and Liver Physiology 290 G511-G518.

Davis ME, Pemberton CJ, Yandle TG, Fisher SF, Lainchbury JG, Frampton CM, Rademaker MT \& Richards M 2007 Urocortin 2 infusion in human heart failure. European Heart Journal 28 2589-2597.

Ebling FJ 2005 The neuroendocrine timing of puberty. Reproduction 129 675-683.

Foster DL, Jackson LM \& Padmanabhan V 2006 Programming of GnRH feedback controls timing puberty and adult reproductive activity. Molecular and Cellular Endocrinology 254-255 109-119.

Kageyama K, Li C \& Vale WW 2003 Corticotropin-releasing factor receptor type 2 messenger ribonucleic acid in rat pituitary: localization and regulation by immune challenge, restraint stress, and glucocorticoids. Endocrinology 144 1524-1532.

Kaplowitz PB 2008 Link between body fat and the timing of puberty. Pediatrics 121 S208-S217.

Lovenberg TW, Chalmers DT, Liu C \& De Souza EB 1995a CRF2 alpha and CRF2 beta receptor mRNAs are differentially distributed between the rat central nervous system and peripheral tissues. Endocrinology 136 4139-4142.

Lovenberg TW, Liaw CW, Grigoriadis DE, Clevenger W, Chalmers DT, De Souza EB \& Oltersdorf T 1995b Cloning and characterization of a functionally distinct corticotropin-releasing factor receptor subtype from rat brain. PNAS 92 836-840.

MacNeilly AS, Crawford JL, Taragnat C, Nicol L \& McNeilly JR 2003 The differential secretion of FSH and LH: regulation through genes, feedback and packaging. Reproduction 61 463-476.
Mauras N, Rogol AD, Haymond MW \& Veldhuis JD 1996 Sex steroids, growth hormone, insulin-like growth factor-1: neuroendocrine and metabolic regulation in puberty. Hormone Research 45 74-80.

Nemoto T, Iwasaki-Sekino A, Yamauchi N \& Shibasaki T 2007 Regulation of the expression and secretion of urocortin 2 in rat pituitary. Journal of Endocrinology 192 443-452.

Ohata H \& Shibasaki T 2004 Effects of urocortin 2 and 3 on motor activity and food intake in rats. Peptides 25 1703-1709.

Perrin MH, Donaldson CJ, Chen R, Lewis KA \& Vale WW 1993 Cloning and functional expression of a rat brain corticotropin releasing factor (CRF) receptor. Endocrinology 133 3058-3061.

Reyes TM, Lewis K, Perrin MH, Kunitake KS, Vaughan J, Arias CA, Hogenesch JB, Gulyas J, Rivier J, Vale WW et al. 2001 Urocortin II: a member of the corticotropin-releasing factor (CRF) neuropeptide family that is selectively bound by type 2 CRF receptors. PNAS 98 2843-2848.

Sapolsky R, Rivier C, Yamamoto G, Plotsky P \& Vale W 1987 Interleukin-1 stimulates the secretion of hypothalamic corticotropin-releasing factor. Science 238 522-524.

Shupnik MA 1996 Gonadotropin gene modulation by steroids and gonadotropin-releasing hormone. Biology of Reproduction 54 279-286.

Tao J, Zhang Y, Soong TW \& Li S 2006 Urocortin II inhibits the apoptosis of mesenteric arterial smooth muscle cells via L-type calcium channels in spontaneously hypertensive rats. Cellular Physiology and Biochemistry 17 $111-120$.

Vale W, Spiess J, Rivier C \& Rivier J 1981 Characterization of a 41-residue ovine hypothalamic peptide that stimulates secretion of corticotropin and beta-endorphin. Science 213 1394-1397.

Wennink JM, Delemarre-van de Waal HA, Schoemaker R, Schoemaker H \& Schoemaker J 1990 Luteinizing hormone and follicle stimulating hormone secretion patterns in girls throughout puberty measured using highly sensitive immunoradiometric assays. Clinical Endocrinology 33 333-344.

Winters SJ \& Moore JP 2007 Paracrine control of gonadotrophs. Seminars in Reproductive Medicine 25 379-387.

Yamauchi N, Otagiri A, Nemoto T, Sekino A, Oono H, Kato I, Yanaihara C \& Shibasaki T 2005 Distribution of urocortin 2 in various tissues of the rat. Journal of Neuroendocrinology 17 656-663.

Zorrilla EP, Reinhardt LE, Valdez GR, Inoue K, Rivier JE, Vale WW \& Koob GF 2004 Human urocortin 2, a corticotropin-releasing factor (CRF)2 agonist, and ovine CRF, a CRF1 agonist, differentially alter feeding and motor activity. Journal of Pharmacology and Experimental Therapeutics 310 1027-1034.

Received in final form 15 January 2009

Accepted 3 February 2009

Made available online as an Accepted Preprint 3 February 2009 